\title{
Interleukin-11, an interleukin-6-like cytokine, is a promising predictor for bladder cancer prognosis
}

\author{
DEYAO WU ${ }^{1 *}$, JUN TAO $^{2 *}$, JINGJING DING ${ }^{3}$, PING QU $^{1}$, QIANG LU ${ }^{2}$ and WEI ZHANG ${ }^{2}$ \\ ${ }^{1}$ Department of Urology, The Fourth Affiliated Hospital of Nantong Medical College, Yancheng City No. 1 People's Hospital; \\ ${ }^{2}$ Department of Urology, First Affiliated Hospital of Nanjing Medical University; \\ ${ }^{3}$ School of Basic Medical Science, Nanjing Medical University, Nanjing, P.R. China
}

Received August 11, 2012; Accepted November 20, 2012

DOI: $10.3892 / \mathrm{mmr} .2012 .1199$

\begin{abstract}
Numerous studies have suggested that interleukin 11 (IL-11) has roles in human gastric, prostate and bone cancer and endometrial carcinoma. Hence, we evaluated the expression of IL-11 in bladder cancer and the correlation of IL-11 levels and clinicopathological features. The expression of IL-11 in primary human bladder cell culture, human bladder cancer cell lines, transitional cell carcinoma (TCC) and non-cancerous bladder tissues (NATs) were analyzed by western blotting. Enzyme-linked immunosorbent assay (ELISA) for urinary IL-11 was performed to compare the IL-11 levels in healthy subjects and subjects diagnosed with bladder cancer. Our study suggested that the expression of IL-11 in human bladder cancer cell lines and TCC was downregulated compared with primary human bladder cell culture and matched NATs. We also demonstrated reduced urinary levels of IL-11 in subjects with bladder cancer compared with healthy subjects. Furthermore, we revealed that the levels of IL-11 were associated with tumor grade and stage. The results suggested that reduced levels of IL-11 may play an important role in the carcinogenesis and progression of TCC. They also indicated that IL-11 may be a promising predictor for prognosis of TCC.
\end{abstract}

\section{Introduction}

Bladder cancer is one of the most common malignancies worldwide. In the western world it is the seventh most common malignancy among males, following lung, prostate, colon, stomach, liver and esophagus cancer, and is the second most common cause of mortality among genitourinary tumors. It was estimated that in the western world there would be 70,530

Correspondence to: Professor Qiang Lu, Department of Urology, First Affiliated Hospital of Nanjing Medical University, 300 Guangzhou Road, Jiangsu, Nanjing 210029, P.R. China

E-mail: luqiang0405@163.com

${ }^{*}$ Contributed equally

Key words: interleukin-11, bladder cancer, prognosis new cases and 14,680 deaths due to bladder cancer in 2010 (1-3). Bladder cancer is compromised of tumors that exhibit a wide spectrum of clinical behavior. Approximately $90 \%$ of bladder cancers are transitional cell carcinoma (TCC), whereas 5\% are squamous cell carcinomas and $1-2 \%$ are adenocarcinomas $(3,4)$. The most common form of the disease, which accounts for $70-80 \%$ of cases, is usually low-grade, multifocal, superficial and papillary. The less common, muscle invasive form of the disease accounts for $20 \%$ of bladder cancer cases (5). Although major work has been focused on tackling the problem of bladder cancer, our understanding of the molecular and cellular mechanisms that underlie cancer carcinogenesis and progression remains poor.

Patients with low-grade, non-invasive bladder cancer are managed with simple resection and fulguration of the tumor and selective intravesical chemotherapy $(6,7)$. Patients with high-grade non-invasive or muscle invasive cancer are treated with more aggressive therapies, such as immunotherapy for non-muscle invasive lesions and radical cystectomy, chemotherapy and occasionally radiation therapy for muscle invasive disease $(7,8)$. The standard of care, while effective, is associated with a considerable side-effect profile, and $>30 \%$ of patients fail to respond to treatment or suffer recurrent disease within 5 years (9). Therefore, patients with bladder cancer need to be monitored for cancer recurrence or progression. It is also important to predict the prognosis of the patients to enable more active treatment in order to prolong their lives.

Interleukin (IL)-6-like cytokines are characterized by a common signal chain (gp130) in the receptor complex. This family is comprised of polypeptides with a molecular weight of $20 \mathrm{kDa}$, and includes IL-6, IL-11, IL-31, ciliary neurotrophic factor (CNTF), leukemia inhibitory factor (LIF), oncostatin-M (OSM), cardiotropin-1 (CT-1), cardiotropin-like cytokine (CLC) and neuropoietic hormone (NPN). Among these IL-6-like cytokines, IL-11 was first cloned from the primate stromal cell line PU-34 and is expressed by a variety of tissues, such as gut, brain, spinal cord neurons and testes, and hence may have a physiological role in these organs $(10,11)$. IL-11 has been mapped in humans to chromosome 19 at the q13.3-q13.4 locus (12). The genes spans $7 \mathrm{~kb}$ and consists of 5 exons and 4 introns (13). Numerous studies have suggested that IL-11 has roles in human gastric, prostate and bone cancer, and endometrial carcinoma (14). The uterine washing level of 
IL-11 has been found to be elevated and to play a complex role in the progression of endometrial carcinoma. IL-11 was also demonstrated to be upregulated and associated with clinicopathological features in gastric cancer (15). However, no studies have investigated the expression of IL-11 in bladder cancer and the correlation of IL-11 level and clinicopathological features.

In this study, the levels of IL-11 were shown to be downregulated in bladder cancer cell lines and TCC compared with primary human bladder cell culture and NATs. We also showed reduced urinary levels of IL-11 in subjects with TCC compared with healthy subjects. Furthermore, we revealed that the levels of IL-11 were associated with tumor grade and stage. These results suggest that reduced levels of IL-11 may play an important role in the carcinogenesis and progression of TCC. They also indicate that IL-11 may be a promising predictor for the prognosis of TCC.

\section{Materials and methods}

Patients and clinical specimens. Tissue specimens used in this study were collected at the Yancheng City No. 1 People's Hospital. Tissues were obtained after patients provided written informed consent under a general tissue collection protocol approved by the faculty/institutional research committee. Urine samples were obtained from individuals with no previous history of urothelial carcinoma, gross hematuria, active urinary tract infection or urolithiasis and individuals with newly diagnosed TCC. Tissues were snap-frozen in liquid nitrogen. The urine samples were stored at $-80^{\circ} \mathrm{C}$.

Cells and culture conditions. The human bladder cancer cell lines T24, J82, HT-1376, 253J, RT4, TCC-SUP and primary human bladder cell culture were kindly donated by the Jiangsu Province Hospital, the First Affiliated Hospital of Nanjing Medical University. The cells, but not the primary human bladder cell culture, were cultured in RPMI-1640 medium supplemented with $10 \%$ heat-inactivated fetal bovine serum, $100 \mathrm{U} / \mathrm{ml}$ penicillin and $100 \mathrm{mg} / 1$ streptomycin at $37^{\circ} \mathrm{C}$ in a humidified atmosphere containing $5 \% \mathrm{CO}_{2}$. The primary human bladder cell culture was cultured in Eagle's minimum essential medium (EMEM) supplemented with $10 \%$ heatinactivated fetal bovine serum, $100 \mathrm{U} / \mathrm{ml}$ penicillin, $100 \mathrm{mg} / \mathrm{l}$ streptomycin, $0.56 \mu \mathrm{g} / \mathrm{ml}$ amphotericin $\mathrm{B}, 1.0 \mathrm{U} / \mathrm{ml}$ insulin and $10 \mathrm{mM}$ HEPES at $37^{\circ} \mathrm{C}$ in a humidified atmosphere containing $5 \% \mathrm{CO}_{2}$. Cells were subcultured every 2 days using trypsin/EDTA solution (saline containing $0.05 \%$ trypsin, $0.01 \mathrm{M}$ sodium phosphate and $0.53 \mu \mathrm{M}$ EDTA, $\mathrm{pH} 7.4$ ).

Enzyme-linked immunosorbent assay (ELISA) for urinary $I L-11$. The quantitative determination of urinary concentrations of IL-11 was performed using ELISA kits (Quantikine; R\&D Systems, Abingdon, UK). All assays were conducted according to the manufacturer's instructions. Calibration curves were prepared using purified standards. Curve fitting was accomplished by either linear or four-parameter logistic regression according to the manufacturer's instructions.

Western blotting. Primary antibodies used in this study, including IL-11 and $\beta$-actin, were products of Bioworld

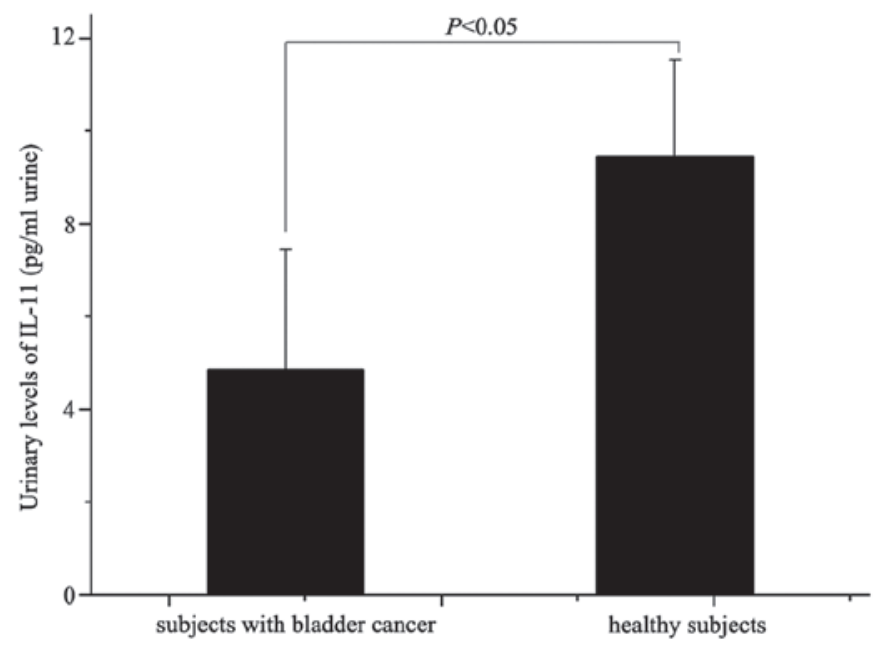

Figure 1. Urinary levels of IL-11 in healthy subjects and subjects with bladder cancer. It was revealed that the urinary levels in subjects diagnosed with bladder cancer were lower compared with healthy subjects $(\mathrm{P}<0.05)$. IL, interleukin.

Technology (Louis Park, MN, USA). Total protein of tissue specimens and cells were prepared using RIPA lysis buffer. The protein concentration in the resulting lysate was determined using the bicinchoninic acid assay. Equal amounts of protein were loaded onto SDS-PAGE and transferred to a PVDF membrane. After blocking with 5\% skimmed milk in TBST, the membranes were incubated overnight with appropriately diluted primary antibody at $4^{\circ} \mathrm{C}$. They were then washed and incubated with the corresponding horseradish peroxidase-conjugated secondary antibody at a 1:2,000 dilution in TBST. The blot was developed with ECL solution (Pierce Biotechnology, Inc., Rockford, IL, USA) and images were obtained using the FluorChem imaging system (Alpha Innotech, CA, USA). The intensity of each spot was read and analyzed with AlphaEaseFC software.

Statistical analysis. Data are presented as the mean \pm standard deviation (SD) and compared using the Student's t-test in Stata 10.0 (College Station, TX, USA). A double-tailed P-value $<0.05$ was considered to indicate a statistically significant difference.

\section{Results}

Urinary levels of IL-11 in healthy subjects and subjects with TCC. First, we examined the expression of IL-11 in 27 healthy subjects and 32 subjects with TCC by using ELISA. The urinary IL-11 levels in healthy subjects were $9.44 \pm 2.09 \mathrm{pg} / \mathrm{ml}$ urine compared with $4.85 \pm 2.60 \mathrm{pg} / \mathrm{ml}$ urine in subjects diagnosed with TCC (Fig. 1). The statistical analysis revealed that the urinary levels in subjects diagnosed with TCC were lower compared with healthy subjects $(\mathrm{P}<0.05)$.

Expression of IL-11 in TCC, NATs, primary human bladder cell culture and bladder cancer cell lines. We also examined the expression of IL-11 in primary human bladder cell culture and bladder cancer cell lines using western blotting. In the present study, we used seven types of bladder cancer cell 

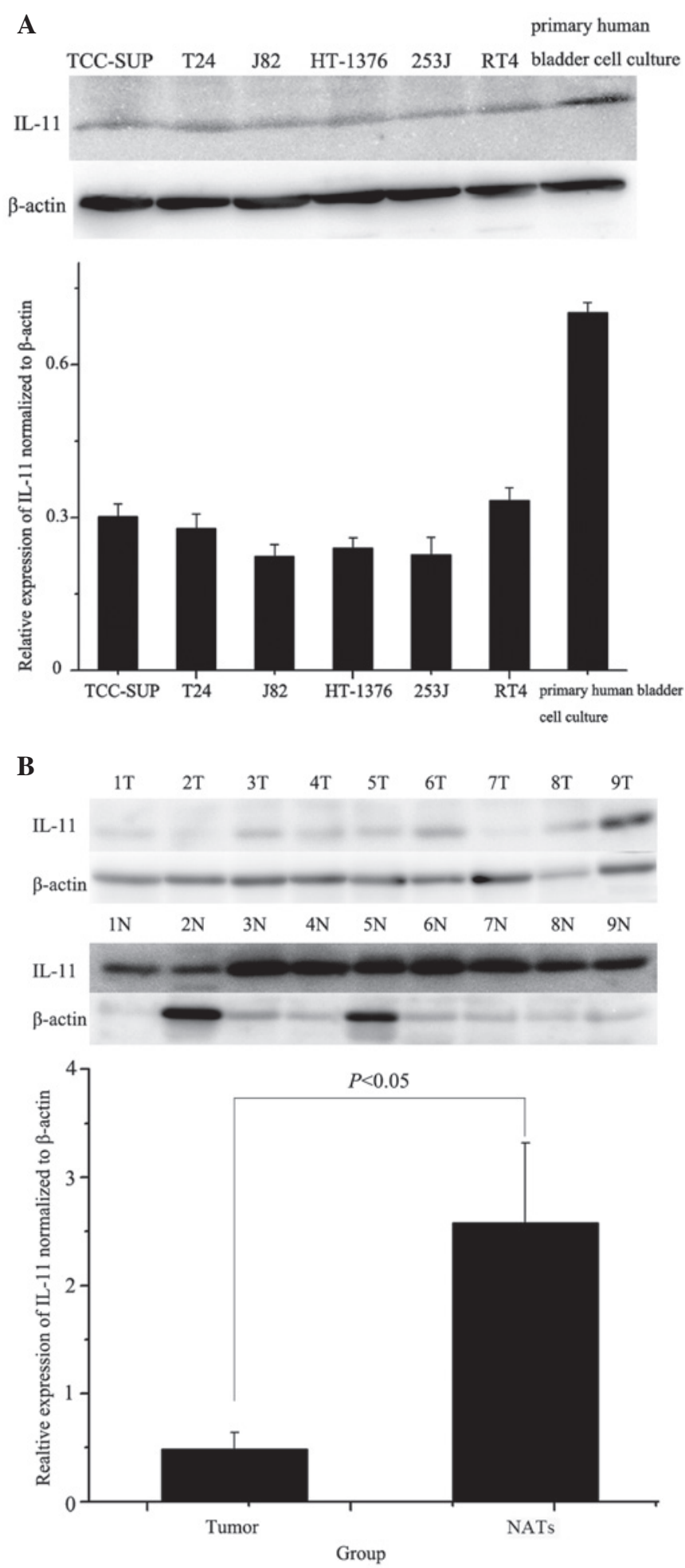

Figure 2. (A) Relative IL-11 protein levels in primary human bladder cell culture and bladder cancer cell lines. The intensity signals in pixels for IL-11 were divided by the respective intensity of $\beta$-actin. The relative IL-11 protein levels were significantly lower in bladder cancer cell lines compared with the primary human bladder cell culture. (B) Relative IL-11 protein levels in paired bladder cancer tissues and the adjacent non-cancerous bladder tissues (NATs). The intensity signals in pixels for IL-11 were divided by the respective intensity of $\beta$-actin. The average relative IL-11 levels of TCC were lower compared with the NATs. TCC, transitional cell carcinoma; IL, interleukin.

lines. The results showed that IL-11 levels in bladder cancer cell lines were significantly lower compared with primary human bladder cell culture. We then compared the expression
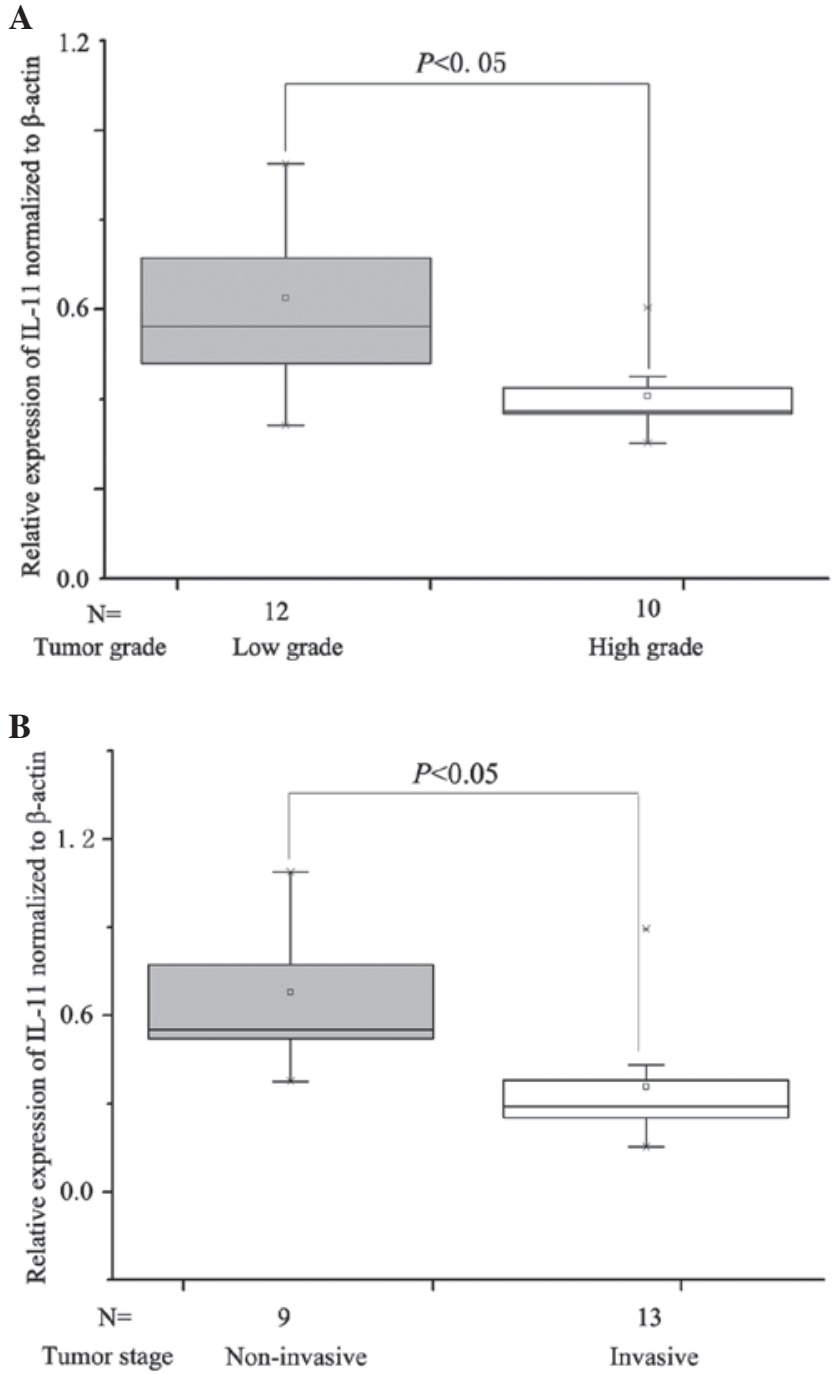

Figure 3. Correlation between IL-11 level and clinicopathological features in patients with bladder cancer. The relative IL-11 levels of patients with TCC have significant correlation with (A) tumor grade and (B) tumor stage. TCC, transitional cell carcinoma; IL, interleukin.

of IL-11 in TCC and NATs. We used 22 paired samples of TCC and NATs. According to the results, IL-11 protein levels in TCC were significantly downregulated compared with NAT samples (Fig. 2). These results demonstrated that IL-11 was downregulated in human bladder cancer cell lines and TCC compared with primary human bladder cell culture and matched NATs.

Correlation between IL-11 level and clinicopathological features in patients with TCC. The expression of IL-11 is associated with clinicopathological features in gastric and endometrial cancer $(16,17)$. Therefore, we examined whether the level of IL-11 was associated with the tumor grade and stage. According to the results, superficial bladder cancer (Tis, Ta and $\mathrm{T}_{1}$ ) had a high level of IL-11 compared with invasive bladder cancer $\left(\mathrm{T}_{2}, \mathrm{~T}_{3}\right.$ and $\left.\mathrm{T}_{4}\right)$; low-grade bladder cancer also had a high level of IL-11 compared with high-grade bladder cancer. The statistical analysis showed that there was a significant association between the IL-11 expression level and the tumor grade and stage (Fig. 3). 


\section{Discussion}

In this study, we presented definitive evidence that IL-11 was downregulated in human bladder cancer cell lines, TCC and urine samples. Our data also showed that there was a significant association between the IL-11 expression level and the tumor grade and stage. To the best of our knowledge, this is the first study demonstrating alterations in expression of IL-11 in human bladder cancer cell lines, TCC and urine samples.

IL-11 is a secreted pleiotropic cytokine first identified in an immortalized primate bone marrow stromal cell line (18). To date, IL-11 has been characterized most extensively as a cytokine with thrombopoietic activity. It was also shown to have a number of additional biological activities, including stimulation of erythropoeisis (19), activation of megakaryocytes (20), modulation of neuronal phenotypes (21), regulation of macrophage precursors (22), promotion of stem cell development (23) and improved colonization of transplanted murine bone marrow cells (24). In addition, IL-11 is capable of stimulating B cell IgG production (25), and osteoblast-derived IL-11 activates bone-resorbing osteoclasts with an associated decrease in de novo bone formation (26).

In several clinical and experimental studies, IL-11 exhibited anti-inflammatory activity $(27,28)$. IL-11 mediates anti-inflammatory activities during chemotherapy-induced oral mucositis (29), acute intestinal ischemia (30) and in Clostridium difficile toxin A-associated intestinal toxicity (31). Directing IL-11 overexpression to the bronchial mucosa or airway epithelium in transgenic mice minimized hyperoxic lung injury and induced focal tissue fibrosis during the ensuing wound-healing response $(32,33)$. These studies clearly show that IL-11 is capable of modulating the severity of inflammation-associated disease, however, the underlying mechanisms remain incompletely understood. In previous studies, IL-11 was demonstrated to act as an anti-inflammatory cytokine through directly reducing the number of macrophages and effectors at the site of inflammation. It has also been shown that IL-11 dampens the release of nitric oxide, TNF- $\alpha$, IL-1 $\beta$, and the immunomodulatory cytokines IL-12, IL-10, TGF- $\beta$ and IL-6 (34).

There is substantial evidence that inflammation plays a direct role in bladder cancer carcinogenesis (35). To date, epidemiological data on urinary tract infections (UTIs) and bladder cancer risk have been conducted in developed countries where $89 \%$ or more of all tumors included in the studies were TCC. UTIs have been positively associated with the risk of bladder cancer in retrospective observational studies. Relative risks in these studies range between 1.4 and 16 for any history of urinary infection versus none. Similar associations have been observed for males and females (35).

Infection may induce tissue and DNA damage by activation of inflammatory cells, generating reactive oxygen and nitrogen species (36-38). Reactive oxygen and nitrogen species can directly produce single- or double-stranded DNA breaks, modify ribonucleic acid, lipids and proteins and modulate cell growth and tumor promotion by activating signal-transduction pathways $(37,39)$. At the site of inflammation, neutrophils, monocytes and macrophages generate a variety of reactive species, including superoxide anion, hydrogen peroxide and nitric oxide $(37,39)$. Inducible nitric oxide synthase protein has been detected in transitional cell tumors of the bladder, but not in bladders of healthy patients (40). In this study, the results showed that IL-11 was downregulated in human bladder cancer cell lines, TCC and urine samples. The downregulation of IL-11 reduced its anti-inflammatory activity by reducing the impact on macrophages, effectors at the site of inflammation and nitric oxide. These results suggested that downregulation of IL-11 is a probable mechanism of bladder cancer carcinogenesis and progression. It may provide us with a promising method to prevent bladder cancer recurrence or progression.

A number of prognostic indicators of bladder cancer have been identified which serve as guides for clinical decisionmaking, recurrence or progression. Clinical staging and histopathological parameters are currently the most commonly used prognostic tools. Of these, the tumor, node and metastasis (TNM) staging system is a well-known prognostic tool used clinically (41). Various prognostic indices such as p53, p21 and $\mathrm{Rb}$ have also been devised by combining these factors (42). Although these prognostic indicators, to a certain extent, aid in the assessment of the severity of the disease, planning management and prediction of recurrence and prognosis, they are not always a good indicator of behavior in individual bladder cancer cases. Advances in molecular biology have provided new tools to make clinical decisions and predict prognosis in human bladder cancer. In this study, we demonstrated downregulation of IL-11 in human bladder cancer cell lines and TCC. It was associated with the finding that urinary levels in subjects diagnosed with TCC were lower compared with healthy subjects. Our results also indicated that invasive, highgrade bladder cancer had a decreased level of IL-11 expression compared with superficial, low-grade bladder cancer. It is demonstrated that the level of IL-11 was associated with tumor grade and stage in TCC. Thus, TCC that expresses a decreased level of IL-11 is more likely to have a poor histological grade and a poor predicted prognosis. Similarly, samples showing lower levels of IL-11 are more likely to fail to respond to treatment, develop recurrence and to have poor survival. These data indicated that IL-11 may be a predictor of prognosis in TCC.

Further study is required to formulate an arbitrary cut-off value for IL-11 in order for it to be of clinical significance to predict prognosis. Future research in this field may explain the downregulation mechanisms and reveal a new predictor in human bladder cancer prognosis.

In conclusion, IL-11 is downregulated in human bladder cancer cell lines, TCC and urine samples. Its level is associated with tumor grade and stage. We propose that reduced levels of IL-11 may be a mechanism of bladder cancer carcinogenesis and progression. It also may be a predictor of prognosis in TCC. Patients with reduced levels of IL-11 should receive more active treatment due to the more aggressive biology of TCC. Besides its prognostic value, IL-11 may represent a promising method for the development of adjuvant therapy for TCC.

\section{Acknowledgements}

This study was supported by the program of the Key Medical Department of Jiangsu Province, Department of General Surgery of Jiangsu Province Hospital and Department of Urology of Jiangsu Province Hospital. 


\section{References}

1. Jemal A, Bray F, Center MM, Ferlay J, Ward E and Forman D: Global cancer statistics. CA Cancer J Clin 61: 69-90, 2011.

2. Edwards BK, Ward E, Kohler BA, Eheman C, Zauber AG, Anderson RN, Jemal A, Schymura MJ, Lansdorp-Vogelaar I, Seeff LC, van Ballegooijen M, Goede SL and Ries LA: Annual report to the nation on the status of cancer, 1975-2006, featuring colorectal cancer trends and impact of interventions (risk factors, screening, and treatment) to reduce future rates. Cancer 116 : 544-573, 2010.

3. Kirkali Z, Chan T, Manoharan M, Algaba F, Busch C, Cheng L, Kiemeney L, Kriegmair M, Montironi R, Murphy WM, Sesterhenn IA, Tachibana M and Weider J: Bladder cancer: epidemiology, staging and grading, and diagnosis. Urology 66 : 4-34, 2005

4. Heney NM: Natural history of superficial bladder cancer. Prognostic features and long-term disease course. Urol Clin North Am 19: 429-433, 1992.

5. Bellmunt $\mathrm{J}$ and Guix M: New agents for bladder cancer. Ann Oncol 21 (Suppl 7): vii56-58, 2010.

6. Pawinski A, Sylvester R, Kurth KH, Bouffioux C, van der Meijden A, Parmar MK and Bijnens L: A combined analysis of European Organization for Research and Treatment of Cancer, and Medical Research Council randomized clinical trials for the prophylactic treatment of stage TaT1 bladder cancer. European Organization for Research and Treatment of Cancer Genitourinary Tract Cancer Cooperative Group and the Medical Research Council Working Party on Superficial Bladder Cancer. J Urol 156: 1934-1940, 1996.

7. Sylvester RJ, Oosterlinck W and van der Meijden AP: A single immediate postoperative instillation of chemotherapy decreases the risk of recurrence in patients with stage Ta $\mathrm{T} 1$ bladder cancer: a meta-analysis of published results of randomized clinical trials J Urol 171: 2186-2190, quiz 2435, 2004.

8. Sengupta $S$ and Blute ML: The management of superficial transitional cell carcinoma of the bladder. Urology 67: 48-54, 2006.

9. Dovedi SJ and Davies BR: Emerging targeted therapies for bladder cancer: a disease waiting for a drug. Cancer Metastasis Rev 28: 355-367, 2009.

10. Teramura M,Kobayashi S, Yoshinaga K, Iwabe K and Mizoguchi H: Effect of interleukin 11 on normal and pathological thrombopoiesis. Cancer Chemother Pharmacol 38: S99-S102, 1996.

11. von Rango U, Alfer J, Kertschanska S, Kemp B, Muller-Newen G, Heinrich PC, Beier HM and Classen-Linke I: Interleukin-11 expression: its significance in eutopic and ectopic human implantation. Mol Hum Reprod 10: 783-792, 2004.

12. McKinley D, Wu Q, Yang-Feng T and Yang YC: Genomic sequence and chromosomal location of human interleukin-11 gene (IL11). Genomics 13: 814-819, 1992.

13. Grosfeld JL, Du X and Williams DA: Interleukin-11: its biology and prospects for clinical use. JPEN J Parenter Enteral Nutr 23 S67-S69, 1999

14. Yap J, Salamonsen LA, Jobling T, Nicholls PK and Dimitriadis E: Interleukin 11 is upregulated in uterine lavage and endometrial cancer cells in women with endometrial carcinoma. Reprod Biol Endocrinol 8: 63, 2010.

15. Furuya $Y$, Nishio R, Junicho A, Nagakawa $\mathrm{O}$ and Fuse H: Serum interleukin-11 in patients with benign prostatic hyperplasia and prostate cancer. Int Urol Nephrol 37: 69-71, 2005.

16. Sales KJ, Grant V, Cook IH, Maldonado-Perez D, Anderson RA, Williams AR and JabbourHN: Interleukin-11 in endometrial adenocarcinoma is regulated by prostaglandin F2alpha-F-prostanoid receptor interaction via the calcium-calcineurin-nuclear factor of activated $T$ cells pathway and negatively regulated by the regulator of calcineurin-1. Am J Pathol 176: 435-445, 2010.

17. Nakayama T, Yoshizaki A, Izumida S, Suehiro T, Miura S, Uemura T, Yakata Y, Shichijo K, Yamashita S and Sekin I: Expression of interleukin-11 (IL-11) and IL-11 receptor $\alpha$ in human gastric carcinoma and IL-11 upregulates the invasive activity of human gastric carcinoma cells. Int J Oncol 30: 825-833, 2007.

18. Trepicchio WL and Dorner AJ: Interleukin-11. A gp130 cytokine. Ann NY Acad Sci 856: 12-21, 1998.

19. Du XX and Williams DA: Interleukin-11: a multifunctional growth factor derived from the hematopoietic microenvironment. Blood 83: 2023-2030, 1994.
20. Weich NS, Wang A, Fitzgerald M, Neben TY, Donaldson D, Giannotti J, Yetz-Aldape J, Leven RM and Turner KJ: Recombinant human interleukin-11 directly promotes megakaryocytopoiesis in vitro. Blood 90: 3893-3902, 1997.

21. Du X, Everett ET, Wang G, Lee WH, Yang Z and Williams DA Murine interleukin-11 (IL-11) is expressed at high levels in the hippocampus and expression is developmentally regulated in the testis. J Cell Physiol 168: 362-372, 1996.

22. Musashi M, Yang YC, Paul SR, Clark SC, Sudo T and Ogawa M: Direct and synergistic effects of interleukin 11 on murine hemopoiesis in culture. Proc Natl Acad Sci USA 88: 765-769, 1991

23. Musashi M, Clark SC, Sudo T, Urdal DL and Ogawa M: Synergistic interactions between interleukin-11 and interleukin- 4 in support of proliferation of primitive hematopoietic progenitors of mice. Blood 78: 1448-1451, 1991.

24. Holyoake TL, Freshney MG, McNair L, Parker AN, McKay PJ, Steward WP, Fitzsimons E, Graham GJ and Pragnell IB: Ex vivo expansion with stem cell factor and interleukin-11 augments both short-term recovery posttransplant and the ability to serially transplant marrow. Blood 87: 4589-4595, 1996.

25. Yin TG, Schendel P and Yang YC: Enhancement of in vitro and in vivo antigen-specific antibody responses by interleukin $11 . \mathrm{J}$ Exp Med 175: 211-216, 1992.

26. Elias JA, Tang W and Horowitz MC: Cytokine and hormonal stimulation of human osteosarcoma interleukin-11 production. Endocrinology 136: 489-498, 1995.

27. Trepicchio WL, Bozza M, Pedneault G and Dorner AJ: Recombinant human IL-11 attenuates the inflammatory response through down-regulation of proinflammatory cytokine release and nitric oxide production. J Immunol 157: 3627-3634, 1996.

28. Kapina MA, Shepelkova GS, Avdeenko VG, Guseva AN Kondratieva TK, Evstifeev VV and Apt AS: Interleukin-11 drives early lung inflammation during Mycobacterium tuberculosis infection in genetically susceptible mice. PLoS One 6 e21878.

29. Sonis S, Muska A, O'Brien J, Van Vugt A, Langer-Safer P and Keith J: Alteration in the frequency, severity and duration of chemotherapy-induced mucositis in hamsters by interleukin-11. Eur J Cancer B Oral Oncol 31B: 261-266, 1995.

30. Du X, Liu Q, Yang Z, Orazi A, Rescorla FJ, Grosfeld JL and Williams DA: Protective effects of interleukin-11 in a murine model of ischemic bowel necrosis. Am J Physiol 272: G545-G552, 1997.

31. Castagliuolo I, Kelly CP, Qiu BS, Nikulasson ST, LaMont JT and Pothoulakis C: IL-11 inhibits Clostridium difficile toxin A enterotoxicity in rat ileum. Am J Physiol 273: G333-G341, 1997.

32. Zheng T, Zhu Z, Wang J, Homer RJ and Elias JA: IL-11: insights in asthma from overexpression transgenic modeling. J Allergy Clin Immunol 108: 489-496, 2001.

33. Waxman AB, Einarsson $\mathrm{O}$, Seres $\mathrm{T}$, Knickelbein RG, Warshaw JB, Johnston R, Homer RJ and Elias JA: Targeted lung expression of interleukin-11 enhances murine tolerance of $100 \%$ oxygen and diminishes hyperoxia-induced DNA fragmentation. J Clin Invest 101: 1970-1982, 1998.

34. Putoczki T and Ernst M: More than a sidekick: the IL-6 family cytokine IL-11 links inflammation to cancer. J Leukoc Biol 88: 1109-1117, 2010.

35. Michaud DS: Chronic inflammation and bladder cancer. Urol Oncol 25: 260-268, 2007

36. Coussens LM and Werb Z: Inflammation and cancer. Nature 420: 860-867, 2002.

37. Hussain SP, Hofseth LJ and Harris CC: Radical causes of cancer. Nat Rev Cancer 3: 276-285, 2003.

38. Ohshima H, Tatemichi $M$ and Sawa T: Chemical basis of inflammation-induced carcinogenesis. Arch Biochem Biophys 417: 3-11, 2003.

39. Klaunig JE and Kamendulis LM: The role of oxidative stress in carcinogenesis. Annu Rev Pharmacol Toxicol 44: 239-267, 2004.

40. Swana HS, Smith SD, Perrotta PL, Saito N, Wheeler MA and Weiss RM: Inducible nitric oxide synthase with transitional cell carcinoma of the bladder. J Urol 161: 630-634, 1999.

41. Egner JR: AJCC Cancer Staging Manual. JAMA 304: 1726-1727, 2010.

42. Bartsch G, Mitra AP and Cote RJ: Expression profiling for bladder cancer: strategies to uncover prognostic factors. Expert Rev Anticancer Ther 10: 1945-1954, 2010. 